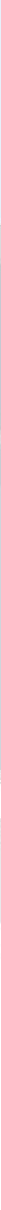

B. Téc. Senac, Rio de Janeiro, v. 43, n. 3, p. 202-219, set./dez. 2017. 


\section{PROGRAMA DE APRENDIZAGEM E A PEDAGOGIA DE PROJETOS}

\section{LEARNING PROGRAM AND PROJECT PEDAGOGY \\ PROGRAMA DE APRENDIZAJE Y PEDAGOGÍA DE PROYECTOS}

Paula Renata Bassan Morais*

* Mestre em Educação, área de concentração Teorias e Políticas em Educação, pela Universidade Nove de Julho. Cursando disciplinas do doutorado em Educação da Universidade Estadual de Campinas (Unicamp). Docente da área de Desenvolvimento Social do Senac. Campinas, São Paulo, Brasil.

E-mail: paula.rbmorais@ sp.senac.br

Recebido para publicação em: 10.10.2016

Aprovado em: 19.6.2017

\section{Resumo}

Este trabalho relata a experiência construída, ao longo de um ano, com jovens aprendizes do curso Aprendizagem Profissional Comercial em Serviços Administrativos, ficha técnica - 8987, do Senac em Campinas, no estado de São Paulo. Esta turma foi considerada uma turma-piloto para a experiência de vivências inovadoras na organização curricular do curso, alinhado com a proposta pedagógica do Senac - SP. O relato deste estudo de caso parte da experiência da autora participante do projeto.

Palavras-chave: Pedagogia de Projetos. Programa de Aprendizagem. Metodologia.

\section{Abstract}

This work reports the experience built over a one-year time, including young apprentices from the course Commercial Professional Learning in Administrative Services, technical file 8987, delivered by Senac in Campinas, São Paulo state. This class was considered to be a pilot group for the innovative experience trial in the set-up of course curriculum, aligned with Senac - SP pedagogical approach. The report of this case study based on the experience of the author as a project participant.

Keywords: Projects Pedagogy. Learning Program. Method. 


\section{Resumen}

Este trabajo relata la experiencia construida, a lo largo de un año, con jóvenes aprendices del curso Aprendizaje Profesional Comercial en Servicios Administrativos, ficha técnica - 8987, de Senac en Campinas, en el estado de São Paulo. Este grupo fue considerado un piloto para experimentar las vivencias innovadoras en la organización curricular del curso, alineado con la propuesta pedagógica de Senac - SP. El relato de este estudio de caso se basa en la experiencia de la autora participante del proyecto.

Palabras clave: Pedagogía de Proyectos. Programa de Aprendizaje. Metodología.

\section{Introdução}

A intenção da pesquisa foi perceber as novas práticas educacionais existentes na literatura sobre Educação, atrelando com a proposta da Pedagogia por Projetos. Seu referencial pedagógico está ancorado na concepção construtivista da aprendizagem e parte da premissa de que aprender não é reproduzir conteúdo, mas ser capaz de elaborar uma representação pessoal sobre a realidade.

A partir da vivência de situações diferenciadas, os jovens aprendizes foram estimulados a ressignificar seus conhecimentos, construindo novos saberes. Os docentes acompanharam o desenvolvimento de cada um, atuando ora como mediadores ora como facilitadores, ou ainda, como consultores. Esta estratégia pedagógica pode ser um instrumento poderoso para o desenvolvimento de competências na área educacional.

\subsection{Programa de Aprendizagem no Brasil}

O Brasil passou por uma fase histórica de democratização no fim da década de 1980. Nessa época, houve alterações na Constituição Federal, entre as quais a inclusão do artigo 227, que intensifica o olhar perante a criança e o adolescente brasileiro.

Em 1990, o Estatuto da Criança e do Adolescente (ECA) tem como objetivo a mudança do paradigma anteriormente estabelecido pelo Código de Menores, por meio da doutrina da proteção integral, que passa a entender crianças e adolescentes enquanto sujeitos de direitos.

Em 1998, com a Emenda Constitucional n. 20, estabeleceu-se que a idade mínima de admissão no trabalho fosse elevada de 14 para 16 anos, porém,
Aprender não

é reproduzir conteúdo, mas ser capaz de elaborar uma representação pessoal sobre a realidade

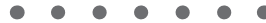


admitindo a possibilidade de o adolescente trabalhar como aprendiz a partir dos 14 anos de idade.

Dois anos após a Emenda Constitucional n. 20, foi aprovada a Lei n. 10.097/2000, que reformulou a concepção de aprendizagem, no sentido de promover a inserção do adolescente no mercado de trabalho. Além disso, esta lei visou a direitos trabalhistas e previdenciários e à participação de entidades assistenciais sem fins lucrativos, entre as quais se pode elencar empresas dos serviços sociais autônomos, como o Senac, que já tinha por objetivo proporcionar a aprendizagem desde os anos de 1940.

Com a nova lei implantada, surge a necessidade de se repensar o atendimento dispensado aos adolescentes, com o objetivo de proporcionar a formação profissional. A Lei aponta a responsabilidade dos órgãos de fiscalização para o acompanhamento e orientação dos serviços implementados e que estejam compatíveis com as diretrizes da legislação.

Observa-se, no País, um movimento intenso de jovens procurando sua entrada no mercado de trabalho. O contrato de aprendizagem é um contrato de trabalho especial, ajustado por escrito e por tempo determinado, em que o empregador se compromete a assegurar ao maior de 14 (quatorze) e menor de 24 (vinte e quatro anos), inscrito em programa de aprendizagem, formação técnica-profissional metódica, compatível com o seu desenvolvimento físico, moral e psicológico, em contrapartida, o aprendiz deve executar, com zelo e diligência, as tarefas necessárias para essa formação (BRASIL, 2000).

\subsection{Programa de Aprendizagem no Senac}

O Programa Aprendizagem Profissional Comercial em Serviços Administrativos, ficha técnica - 8987, do Senac em São Paulo, tem por objetivo atender à Lei n. 10.097/2000, seus decretos e portarias, proporcionando educação profissional inicial para jovens contratados na condição de aprendizes pelas empresas. Oferece mais uma alternativa para minimizar a disparidade entre as exigências do mercado de trabalho e a qualificação de seus futuros profissionais, além de se constituir em um dos acessos ao mundo do trabalho para jovens sem experiência profissional que, de outra forma, teriam grande dificuldade de inserção no cenário atual.

Desde sua implantação, em 2003, o Programa de Aprendizagem do Senac em Campinas criou condições para aproximadamente 4 mil jovens vivenciarem uma formação que prioriza o desenvolvimento de competências para o aprimoramento pessoal e profissional com posicionamento ético, sustentável e empreendedor. 
O programa tem 12 meses de duração e prevê em seu desenvolvimento 1.333 horas de aprendizagem. É composto por uma parte teórica, desenvolvida em unidade operacional do Senac, e outra prática, operacionalizada pela empresa contratante do aprendiz.

Cada módulo apresenta carga horária teórica de 200 horas de aprendizagem teórica, acompanhado de 466 horas e 30 minutos de aprendizagem prática no módulo I e a mesma carga horária para o módulo II.

O plano de aprendizagem do Senac São Paulo (2016) relata que

Ao final do programa, o jovem será capaz de participar de ações de organização e operação geral dos serviços administrativos de empresas, compreendendo os processos de funcionamento das áreas e departamentos. Adotará atitude negociadora, sustentável, ética e cidadã, a fim de facilitar o fluxo dos processos da empresa em que está inserido e ter mais embasamento para definir escolhas relativas à permanência nela ou identificação e busca de novas perspectivas.

Quando se iniciou, no dia 5 de maio de 2014, a turma 19/14, que ficou intitulada Turma-piloto da Aprendizagem, no Senac em Campinas, foi um momento marcante de se pensar um novo formato para a aplicação do curso Aprendizagem Profissional Comercial em Serviços Administrativos.

Em momento algum pensou-se na possibilidade de se desestruturar o plano de curso, os objetivos gerais e as competências do programa. O intuito era aprofundar as pesquisas e desmembrar cada tópico apresentado. O que se discutia muito nas reuniões era por que uma Proposta Pedagógica tão rica em detalhes, na prática, era pouco visualizada.

Percebeu-se, então, que ao longo da história do Senac, o modelo tecnicista sempre foi o embasamento teórico. Mas a Instituição está vivenciando um momento como que mágico de transformação nesta história da educação. O Senac está há vários anos intensificando o seu olhar sistêmico em relação ao aluno. A educação profissional pode, sim, estar intimamente ligada com uma educação integradora.

Ao esmiuçar a proposta pedagógica do Senac, houve a condição de buscar alternativas diferenciadas para trabalhar com estes jovens aprendizes. Fazer com que a distância entre o modelo tradicional de educação do século 19, com docentes do século 20 e alunos do século 21 entre em sintonia e conexão.

O primeiro passo foi em relação à organização curricular. Não se objetivava separar, em "caixas fechadas", as unidades de cada módulo do programa. Se o que é mais importante são as competências e a carga horária modular, por que não recriar uma organização curricular que deixasse aberto o momento oportuno para se aprender? 
No quadro a seguir, identifica-se a organização curricular do programa e também como ela foi realizada com a turma 19/14.

Quadro 1 - Organização Curricular Turma 19/14

\begin{tabular}{|c|c|c|c|c|}
\hline \multicolumn{5}{|c|}{ Organização Curricular } \\
\hline $\begin{array}{c}\text { Turma I } \\
9 / 14\end{array}$ & \multicolumn{4}{|c|}{ Programa Aprendizagem em Serviços Administrativos - Senac Campinas } \\
\hline \multirow{4}{*}{$\begin{array}{l}\text { Módulo I - } \\
200 \text { horas }\end{array}$} & \multicolumn{2}{|l|}{ Módulo I } & \multicolumn{2}{|l|}{ Módulo II } \\
\hline & Ambientação Profissional I & $\begin{array}{c}90 \\
\text { horas }\end{array}$ & Ambientação Profissional II & $\begin{array}{c}40 \\
\text { horas }\end{array}$ \\
\hline & $\begin{array}{l}\text { Informática Aplicada à } \\
\text { Corporação }\end{array}$ & $\begin{array}{c}30 \\
\text { horas }\end{array}$ & $\begin{array}{c}\text { Saúde e Segurança no } \\
\text { Trabalho }\end{array}$ & $\begin{array}{c}26 \\
\text { horas }\end{array}$ \\
\hline & $\begin{array}{l}\text { Organização dos Serviços } \\
\text { Administrativos e } \\
\text { Comerciais }\end{array}$ & $\begin{array}{c}60 \\
\text { horas }\end{array}$ & $\begin{array}{c}\text { Rotinas Básicas nos } \\
\text { Serviços Administrativos e } \\
\text { Comerciais }\end{array}$ & $\begin{array}{c}60 \\
\text { horas }\end{array}$ \\
\hline \multirow{4}{*}{$\begin{array}{l}\text { Módulo } \\
\text { II - } 200 \\
\text { horas }\end{array}$} & Atitude Empreendedora & $\begin{array}{c}20 \\
\text { horas }\end{array}$ & $\begin{array}{l}\text { Responsabilidade } \\
\text { Socioambiental }\end{array}$ & $\begin{array}{c}26 \\
\text { horas }\end{array}$ \\
\hline & & & Qualidade no Atendimento & $\begin{array}{c}30 \\
\text { horas }\end{array}$ \\
\hline & & & $\begin{array}{l}\text { Tendências e Perspectivas } \\
\text { em Gestão e Negócios }\end{array}$ & $\begin{array}{c}18 \\
\text { horas }\end{array}$ \\
\hline & Aprendizagem no Senac & $\begin{array}{c}200 \\
\text { horas }\end{array}$ & Aprendizagem no Senac & $\begin{array}{r}200 \\
\text { horas }\end{array}$ \\
\hline
\end{tabular}

Fonte: Senac São Paulo (2016).

Vê-se que em questões administrativas a diferença apareceu no diário, sendo as competências atingidas registradas aleatoriamente, de acordo com o desenvolvimento da turma.

A proposta pedagógica do Senac em São Paulo privilegia o desenvolvimento de competências profissionais, assumindo uma postura com relação à aprendizagem e ao ensino em que a ação docente propicie ao aluno o aprender a aprender e o desenvolvimento da percepção analítica, do raciocínio hipotético e da solução sistemática de problemas, de modo a assegurar o saber, o saber fazer, o saber ser e o saber conviver - condições básicas para a autonomia individual e profissional. 
Neste momento, foram unidas todas as competências do módulo e o docente tinha em mãos os temas e o conteúdo a serem trabalhados. A intenção não era ensinar um tema em cada aula, mas observar e estimular os jovens aprendizes a buscarem refletir sobre sua prática na empresa, sobre sua vida escolar e familiar, seriam assim os temas que seriam estudados. Ficou muito claro para os docentes que a maioria dos temas apontados pelos jovens faziam uma conexão direta com as competências sugeridas no programa. Assim, o jovem aprendia porque aquilo tinha significado para ele naquele exato momento do curso. Ele se sentia motivado, pois a sua voz e o seu momento de vida faziam sentido com tudo o que ele estava aprendendo no curso.

Percebeu-se, inclusive, que isto ajudou em relação à evasão e às faltas durante todo o processo do programa.

\section{Metodologia}

Por meio da metodologia ativa de aprendizagem que visa oferecer a reflexão sobre a ação e o desenvolvimento de competências profissionais, foi possível conhecer os interesses dos alunos para mediar unindo estes temas, que foram se desenvolvendo em habilidades mútuas, e incrementando a convivência entre pessoas, ampliando os espaços para o saber e o conhecimento, facilitando o processo de aprendizado, democratizando o acesso e ampliando as possibilidades do ensinar e do aprender a ser, a fazer e a conviver (DELORES, 2000). Além disso, a metodologia foi alinhada com a proposta pedagógica do Senac, de trabalhar com os jovens aprendizes por meio de projetos.

Na sociedade da informação, o docente já não pode ser considerado o único detentor de um saber que apenas lhe basta transmitir. É preciso ser capaz de se orientar no meio dos saberes, tornando-se, de algum modo, parceiro de um saber coletivo, que lhe compete organizar situando-se, decididamente, na vanguarda do processo de mudança.

As exigências do mundo contemporâneo impõem que se ofereça aos alunos competências básicas que possibilitem o desenvolvimento de conhecimentos, habilidades e atitudes que, por sua vez, permitam sua adaptação e permanência no mercado de trabalho, bem como sua formação como cidadãos críticos e reflexivos, capazes de exercer uma cidadania participante na construção de uma sociedade justa e solidária.

Neste contexto, revisita-se algumas literaturas e reflete-se muito sobre o movimento que veio a ser conhecido como Escola Nova, fruto de pesquisadores europeus como Montessori, Decroly, Claparède e outros.
-

$\mathrm{Na}$

sociedade da informação, o docente já não pode ser considerado o único detentor de um saber que apenas Ihe basta transmitir 
Na América do Norte, dois grandes representantes, John Dewey e seu discípulo William Kilpatrick, são considerados criadores do "Método de Projetos", cuja essência pretendia romper com a passividade do ensino e partir para uma metodologia ativa, dinâmica e criativa.

No Brasil, as ideias foram propagadas pelo renomado professor Anísio Teixeira e por Lourenço Filho na década de 1930.

Já nessa época, a discussão estava embasada na concepção de que "educação é um processo de vida e não uma preparação para a vida futura e a escola deve representar a vida presente - tão real e vital para o aluno como a que ele vive em casa, no bairro ou no pátio" (DEWEY, 1897). De Dewey veio principalmente a ideia de que "o pensamento tem sua origem numa situação problemática".

Outros autores brasileiros também amparam esta concepção de educação, como Nogueira (2001), Torres Santomé (1998), Morin (2001), Hernández e Ventura (1998), Hernández (1998), Fazenda (1995), Lüdke (2003), Freire (1996), Pacheco e Pacheco (2008) e Leite (1994).

Assim, ora de forma mais próxima ora mais distante, a educação brasileira passou a conviver com experiências inovadoras, com o método de projetos, os centros de interesse, as unidades de trabalho, o trabalho por temas geradores, a Pedagogia de Projetos. Apesar das singularidades de cada uma delas, um sentido comum emerge entre todas as propostas: ensinar os alunos a pesquisar a partir dos problemas relacionados a situações da vida real, o que significa desenvolver estratégias para que eles descubram como buscar o conhecimento ao longo de toda a sua vida, compreensão "que se realiza mediante o diálogo, a pesquisa a partir das fontes diversas de informação e a expressão construtivista, mediante diferentes formatos (escritos, dramatizados, visuais, ...) do percurso realizado", afirma Hernández (1998, p. 51).

Não se trata de propor a eliminação das disciplinas, mas a criação de movimentos que levem ao estabelecimento de relações entre as mesmas, tendo como ponto de convergência a ação que se desenvolve em um trabalho cooperativo e reflexivo. Assim, alunos e professores - sujeitos de sua própria ação - engajam-se em um processo de pesquisa, de redescoberta e de construção coletiva. Ao compartilhar ideias, ações e reflexões, cada participante é, ao mesmo tempo, "ator" e "autor" do processo.

Uma coisa é tida como consensual atualmente. Trabalhar com projetos não se constitui "um método". E não existe cartilha mágica para se ensinar a pedagogia por projetos. Tudo acontece no momento, pode-se até planejar e levar opções de atividades, aulas, dinâmicas, mas isto tudo se torna plano B. O plano A é ouvir atentamente o que os alunos estão trazendo e ser um 
mediador do que os alunos falam com as competências a serem aprendidas no programa.

Falar em método em relação à prática escolar é fazer referência à aplicação de uma fórmula ou uma série de regras. Método, em sua concepção filosófica, seria uma maneira concreta de proceder, isto é, de aplicar o pensamento.

O docente tem um momento crucial em suas mãos. Saber ouvir. Tirar sua "armadura" de docente, carregada de respostas, conceitos, PowerPoint, pen drive, textos, filmes prontos. Esta "armadura" de docente pode ser importante apenas em alguns poucos momentos do programa.

Bastos (2006, p. 63) apresenta uma conceituação de Metodologias Ativas como "processos interativos de conhecimento, análise, estudos, pesquisas e decisões individuais ou coletivas, com a finalidade de encontrar soluções para um problema". Nesse caminho, o docente atua como facilitador ou orientador para que o discente faça pesquisas, reflita e decida por ele mesmo o que fazer para atingir os objetivos estabelecidos. Segundo o autor, trata-se de um processo que oferece meios para que se possa desenvolver a capacidade de análise de situações.

Trabalhar com projetos não se trata apenas de uma técnica atraente para transmitir aos alunos o conteúdo das matérias, significa, de fato, uma mudança de postura, uma forma de repensar a prática pedagógica e as teorias que lhe dão sustentação.

Segundo Dewey (apud FREITAS, 2003), um projeto prova ser bom se for suficientemente completo para exigir uma variedade de respostas diferentes dos alunos e permitir, a cada um, trazer uma contribuição que lhe seja própria e característica. Essas respostas resultam de uma aprendizagem significativa de conceitos, adquirida pelo aluno durante o processo de ensino e aprendizagem.

Leite (1994), ao pensar no desenvolvimento de um projeto, cita quatro momentos importantes. 1) Problematização: é o ponto de partida do projeto. Nessa etapa inicial, os alunos irão expressar suas ideias, crenças, conhecimento sobre o problema em questão. Este passo é fundamental, pois dele depende todo o desenvolvimento do projeto. Os alunos não entram na escola como se fossem uma folha em branco; já trazem, em sua bagagem, hipóteses explicativas, concepções sobre o mundo que os cerca. E é dessas hipóteses que a intervenção pedagógica precisa partir, pois, dependendo do nível de compreensão inicial dos alunos, é evidente que o processo toma um ou outro caminho. É na fase de problematização que o professor detecta o que os alunos já sabem e o que ainda não sabem sobre o tema em questão. É também a partir das questões levantadas nesta etapa que o projeto é organizado pelo grupo. 2) Desenvolvimento: é o momento quando se 
As competências norteiam o planejamento, e não as disciplinas ou os conteúdos como tradicionalmente

se tem como referência criam as estratégias para buscar respostas às questões e hipóteses levantadas na problematização. Aqui, também, a ação do sujeito é fundamental. Por isso, é preciso que os alunos se defrontem com situações que os obriguem a confrontar pontos de vista, rever suas hipóteses, colocar-se novas questões, confrontar-se com novos elementos postos pela Ciência. Para isso, é preciso que se criem propostas de trabalho que exijam a saída do espaço escolar, a organização em pequenos e grandes grupos, o uso de biblioteca, a vinda de pessoas convidadas à escola, entre outras ações. Nesse processo, os alunos têm que utilizar todo o conhecimento que têm sobre o tema e se defrontar com conflitos, inquietações que levarão ao desequilíbrio de suas hipóteses iniciais. 3) Síntese: em todo este processo, as convicções iniciais vão sendo superadas e outras, mais complexas, vão sendo construídas. As novas aprendizagens passam a fazer parte dos esquemas de conhecimento dos alunos e vão servir de conhecimento prévio para outras situações de aprendizagem. 4) Avaliação: avalia-se todo o processo de desenvolvimento do projeto, considerando-se a autoavaliação pelos alunos, a avaliação das equipes de trabalho e avaliação das estratégias de ensino e aprendizagem utilizadas para alcançar os fins propostos. Nesse sentido, a avaliação deve ser constante e ao longo do processo, garantindo a oportunidade de ajustes que o melhorem. Apesar de explicitar estes momentos dentro do desenvolvimento de um projeto, é importante frisar que se trata de um processo, e não de etapas estanques. A compreensão da metodologia como técnica é comum na cultura escolar e dela vem a significação e redução da pedagogia de projetos enquanto uma técnica de ensino. Porém, a pedagogia de projetos não pode ser uma técnica sujeita a regras pré-determinadas. Os projetos são processos contínuos, que não podem ser reduzidos a uma lista de objetivos e etapas. Trata-se de uma postura que reflete uma concepção do conhecimento como produção coletiva, em que a experiência vivida e a produção cultural sistematizada se entrelaçam, dando significado a aprendizagens construídas.

Deve-se atentar para o fato de que as competências norteiam o planejamento, e não as disciplinas ou os conteúdos como tradicionalmente se tem como referência. Nesta proposta, os conteúdos são considerados como insumos para a resolução dos problemas ou projetos. É importante que estes referenciais norteadores sejam discutidos com os docentes e sirvam como base para avaliar o adequado alinhamento entre a forma como o curso está sendo desenvolvido e estes princípios.

\section{Características da Turma-piloto de Aprendizagem - I9/14}

Os jovens matriculados no Programa de Aprendizagem do Senac em São Paulo, Unidade Campinas, turma 19/14, durante o período de 6 de maio de 2014 a 5 de maio de 2015, participaram como a Turma-piloto da Aprendi- 
zagem, realizando diversas situações diferenciadas por meio da metodologia de trabalho por competências e da pedagogia por projetos.

Analisou-se se esta turma poderia desfrutar de atividades e encontros diferenciados do que as outras turmas da Unidade do Senac em Campinas. A turma 19/14 foi escolhida para piloto por estar iniciando no mesmo período em que foi proposta esta experiência diferente.

A turma tinha 25 alunos, os aprendizes tinham aulas de terça e quinta, das $13 \mathrm{~h} 00$ às $17 \mathrm{~h} 30$ e provinham de oito empresas diferentes. Os docentes que participaram ativamente com os alunos foram: Silvana Terume Koshikene Rodrigues, Maria Silvia Ferreira Alves de Oliveira, Carmen Eloisa Gravalos Greters e Paula Renata Bassan Morais. Alguns docentes também puderam conhecer a turma em alguns encontros por meio da dupla docência.

Os técnicos Gustavo Henrique Escobar Guimarães e Ana Paula Cardoso de Araújo Santos acompanharam todo o processo com o supervisor educacional Estevão de Jesus Bento. Houve também o apoio da gerente Irecê Piazentin Nabuco de Araujo e em seguida, do gerente João Henrique de Freitas Alves. Estas informações foram encontradas nos documentos da Secretaria Escolar do Senac em Campinas.

Não existia uma característica peculiar nestes jovens aprendizes, são jovens, em constante transformação, como os demais. O que se priorizou desde o primeiro encontro foi a interação entre eles. Eles tiveram a oportunidade de vivenciar no início do curso muitos momentos de conversa coletiva.

Não foram pensados conteúdos programáticos, e sim "Quem são estes seres humanos e como eles podem conviver harmoniosamente no coletivo?". Diante das conversas, muitos depoimentos, relatos de vida, sonhos, obstáculos e dificuldades financeiras foram sendo expostos espontaneamente. Neste momento ficou entendido que ali havia se formado um grupo de pessoas que se aceitavam e se observavam como iguais.

A cada período, uma docente ficava com a turma. Às vezes, uma docente ficava um mês com a turma, outra vez, 15 dias, enfim, era aleatório, de acordo com a escala de trabalho. Mas conversava-se muito sobre a turma por e-mails, WhatsApp e reuniões bimestrais.

Os docentes nestas reuniões refletiram para entender seus papéis neste contexto. O mais interessante foi a percepção de que não poderiam se apresentar como docentes, despejando nos jovens toda sua formação, dando a impressão de superioridade. Entraram no ritmo deles, para primeiramente serem conhecidos como indivíduos em constante aprendizado. Isto fez com que a barreira inicial, do imaginário do jovem que se remete às suas lem- 


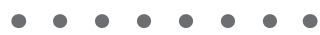

O jovem passa a fazer parte do processo, não fica somente como espectador das informações branças escolares de "obrigação-punição", não interferisse no seu pensar sobre algo novo que estava prestes a começar em sua vida, ser um jovem aprendiz.

O eixo norteador para a elaboração das estratégias de ações fundamentou-se a partir da síntese teórica elaborada sobre duas teorias: a psicologia histórico-cultural de Vigotski (1996) e a pedagogia da libertação de Paulo Freire (1986). Estes autores admitem a importância da mediação e da intencionalidade no processo educativo. Vigotski (1996) compreende que o desenvolvimento humano se dá por meio de processos de interação e mediação. Para este autor, o ser humano constitui-se enquanto que na sua relação com o outro. A mediação ocorre pela possibilidade de interação com signos, símbolos culturais e objetos. Para Freire (1986), a relação que se estabelece entre educador e educando é alicerçada pelo princípio do aprendizado mútuo, não havendo uma verdade absoluta trazida pelo professor para a sala de aula, uma vez que o aluno já traz consigo conhecimentos prévios e, consequentemente, sua visão de mundo.

Quando primeiramente foi pensada a turma-piloto, a primeira intenção foi não seguir o Plano de Aprendizagem. Foram utilizados como norte os documentos institucionais, a Proposta Educacional Pedagógica, o Plano de Curso, as competências a serem desenvolvidas e o perfil do egresso.

Para conseguir organizar esta dinâmica diferenciada, foram elaboradas algumas fases para o aluno. Não seria possível implantar logo no primeiro dia um jeito diferente de educação. A sensação de liberdade e autonomia foram sendo entregues aos poucos para os alunos. As três fases para trabalhar com a pedagogia por projetos foram:

1. Conhecendo: para os jovens que sempre estudaram em escolas formais, com modelos tradicionais, ficou bastante desafiadora a percepção das características de uma nova metodologia. Assim, os jovens solicitaram cópias da lousa, apostilas, textos com perguntas e notas de avaliação. Eles precisaram, primeiro, de um momento de ambientação, para assim conhecerem o quê e como aconteceria a aprendizagem. Neste momento, utilizaram muito diálogo e alguns experimentos de uma nova postura do jovem em relação ao conhecimento. O jovem passa a fazer parte do processo, não fica somente como espectador das informações. Trabalhou-se algumas vezes com aulas elaboradas antecipadamente, com exposições de atividades para realizar a avaliação diagnóstica sobre o grupo. Aos poucos e com uma roda de conversa no início de todos os encontros, os jovens foram incentivados a dialogarem e a buscarem as informações. Para esta turma-piloto, esta fase durou aproximadamente três meses de curso. 
2. Construindo: nesta fase, os jovens já se percebem como parte integrante de uma equipe e gostam de opinar e sugerir o andamento do encontro. Começam a associar as informações e a querer pesquisar sobre assuntos que não conhecem. Sentem a necessidade de visitas à biblioteca, a livros e a compartilhar as informações. É um momento interessante, em que eles conseguem perceber que o outro jovem tem habilidades, assim, aproximam-se e solicitam ajuda. Um aspecto desafiador desta fase são as diferenças de opiniões, pois quando se divergem, os jovens têm propensão a querer que sua opinião seja aceita. Com muita conversa, eles entendem que existe o momento de falar e de ouvir e que o consenso é extremamente importante no mundo do trabalho. Para esta turma-piloto, esta fase durou aproximadamente quatro meses de curso.

3. Consolidando: para consolidar o momento em que eles se percebem protagonistas no processo de aprendizagem e que cada um consegue aprender em seu tempo e em seu ritmo próprio, foram realizados com os jovens alguns momentos de autoavaliação para perceberem suas possibilidades e seus desafios. Fica evidenciado que alguns jovens se sobressaem aos outros, e nesse momento é preciso que eles trabalhem mais em equipe, para não hierarquizar o grupo. Todas as propostas e opiniões são aceitas, às vezes até mesmo para aprenderem que pode dar errado e será preciso refazer, reorganizar e ter um "plano B" para conseguirem realizar determinada tarefa. Também foi observado que nesta fase final do curso estão mais cansados, observadores e críticos. Este momento é muito marcante e se consolida com os depoimentos dos jovens de estarem gostando de participar ativamente de seu aprendizado. Para esta turma-piloto, esta fase durou aproximadamente cinco meses de curso.

Desde o primeiro encontro, foi incentivado o compartilhamento. Compartilhar ideias, sugestões, situações vividas na empresa e na vida pessoal. Esse momento foi fundamental para os jovens se conhecerem. Surgiu entre eles um clima de interação e de equipe.

Eles criaram o nome "Soltar o Verbo", dando a conotação de que é um momento de falar o que está pensando e sentindo. Esses momentos duravam de 10 minutos a uma hora, dependendo do assunto que surgia e dos debates. Nesse instante, o docente sempre mediava a conversa e quando surgia uma temática próxima a uma competência a ser desenvolvida, incentivava aquele assunto. Também foi possível perceber atitudes e habilidades a serem desenvolvidas ou já adquiridas pelos jovens. Assim, surgia o encontro e o que eles iriam desenvolver naquele dia era um norte para um próximo encontro. Esse momento perdurou por todo a ano e foi o alicerce para trabalhar as competências do programa.

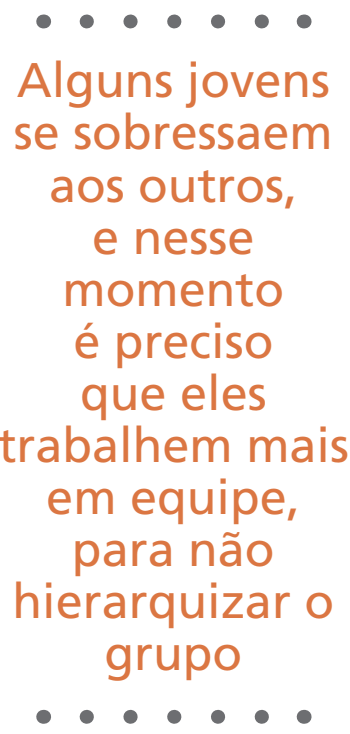

Alguns jovens sobressaem

a outros, e nesse momento e preciso que eles trabalhem mais em equipe, para não hierarquizar o grupo

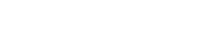

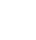

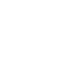


Houve um momento, quase no fim do módulo I, em que os docentes se perguntaram se realmente os jovens estavam aprendendo e, para ter certeza, deram aos alunos uma folha com todas as competências do módulo I. Para analisar, a cor que marcava o que aprendeu deveria também explicar como e quando aprendeu. E na cor que demarcava que não aprendeu, os jovens precisavam apontar como gostaria de aprender aquela competência. Foi um momento muito importante a até avaliativo do trabalho docente. Percebeu-se que $90 \%$ das competências os jovens assinalaram que haviam aprendido. Como tinham ainda alguns encontros para encerrar o módulo I, os docentes se propuseram a atender as solicitações dos jovens para aprender as competências faltantes.

Percebeu-se que todas as competências foram atingidas e de uma maneira muito aleatória. As unidades do programa não foram seguidas, e sim as informações e conversas entre os jovens no momento "Soltar o Verbo".

Estas competências ora se juntavam ora ficavam fragmentadas ora os jovens aprendizes envolviam tudo em um único objetivo: ter uma ação real. Estes eram momentos de muita riqueza de conhecimentos coletivos, em que criavam e propunham ações e cada ação associada a outra e aos poucos se tornavam um projeto. A turma-piloto realizou dois grandes projetos e vários projetos de curta duração "linkando" competências variadas. Todo o processo foi registrado e foram trabalhados os detalhes trazidos pelos alunos. Em um determinado momento, houve a necessidade de realizar a parte escrita e elaborar um portfólio dos projetos. Neste instante, realizaram uma teia para perceber tudo o que haviam aprendido, demonstrada no Gráfico 1.

\section{Gráfico 1 - Programa Economia Solidária}

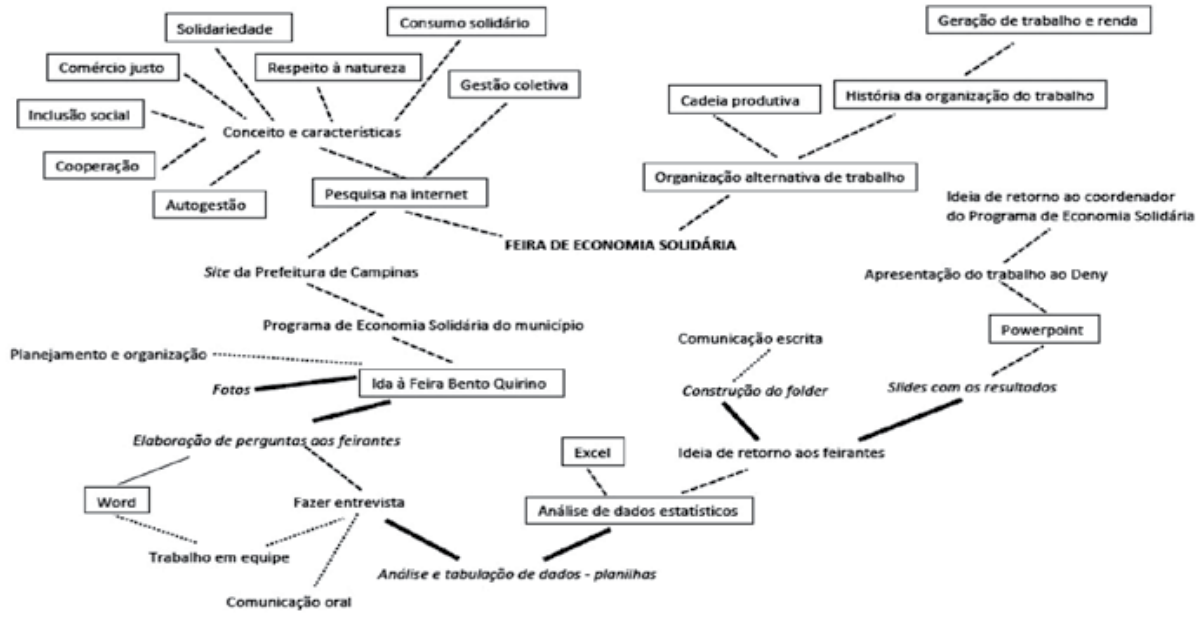

Fonte: Alunos da Turma-piloto de Aprendizagem - 19/14.

No módulo II, percebeu-se que algumas competências não apareciam nos assuntos dos jovens aprendizes, então eles foram incentivados a dar uma 
aula expositiva. Para estranhamento, quando começava o tema da aula, logo eles se articulavam para realizar atividades sobre aquele tema. Isto mostrou que a dinâmica que os docentes haviam pensado sobre as três fases surtiu o efeito esperado e se percebeu naquele instante que os jovens estavam consolidando a aprendizagem com autonomia.

Os jovens foram responsáveis por todo o andamento do programa. As atividades culturais, as visitas orientadas, as atividades em sala ou fora dela, os momentos apropriados de idas ao laboratório de informática e biblioteca, momentos de encontros com pais e empresas e momentos de confraternizações. Eles perceberam que o Senac em Campinas tem um volume muito grande de alunos e souberam entender que, para utilizar os espaços, precisavam se organizar previamente. Havia momentos em que um assunto era "guardado no estacionamento de ideias", para conseguir prosseguir no momento adequado.

Foram realizados registros diários sobre cada encontro. Estes registros foram detalhados com situações importantes. O objetivo era passar para as outras duas docentes que não estavam presentes a sensação e as avaliações daquele encontro. Ficou um documento extenso de mais de 50 páginas, que marcou a passagem dos docentes por esta turma. Este registro era realizado logo após o término do encontro, para gravar os detalhes.

A etapa de avaliação esteve presente em todo o processo: em momentos de avaliação coletiva, de depoimento oral e escrito, de autoavaliação, de trocas de conhecimentos entre grupos, de apresentações para pais e empresas, dentre outros. Atualmente, está sendo realizada a fase de divulgação do trabalho para outras Unidades do Senac da região de Campinas.

\section{Considerações finais}

Não existe uma fórmula e não foi elaborada uma cartilha para ser seguida. Este nunca foi o objetivo do projeto, que queria, sim, compartilhar experiências, trocar informações e estar em constante aprendizado. Cada docente e cada turma tem seu jeito e características próprios. Trabalhar com projetos envolve este olhar minucioso para dentro, e nunca copiar o que se tem fora.

Também foi reparado que não houve somente acertos. Os erros aconteceram e incentivaram a dar atenção aos detalhes diários da turma. Um aprendizado importante foi em relação ao olhar docente enquanto educador. Os participantes deste projeto se reconheceram como educadores sociais em tempo integral, lidando com um educando em uma fase diferente na história da educação. Os modelos mentais de quando estavam na graduação não podem ser levados como o modelo único e correto de atuação docente. Eles

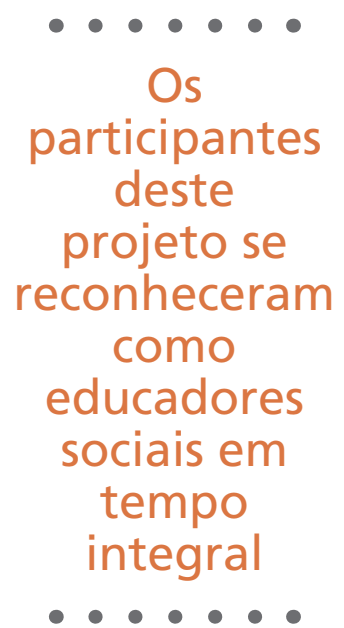


podem ser uma base, mas os profissionais precisam estar atentos às novidades e atualidades principalmente em relação ao ser humano. Parafraseando Rubem Alves, a diferença entre professores e educadores está no olhar. Os olhos do professor olham primeiro para os saberes. Seu dever é cumprir o programa. Depois, eles olham para os alunos, para ver se eles aprenderam os saberes. Para os professores, saberes são fins, alunos são meios. Os olhos dos educadores, ao contrário, olham primeiro para os alunos. Eles querem que os alunos degustem os saberes. Todo saber deve ser saboroso.

Não basta ter o conhecimento técnico, é fundamental o conhecimento sobre o ser humano em construção que está à sua frente. Foi possível observar inúmeras riquezas de conhecimentos ao despertar em cada um a vontade de aprender coisas novas. Desde o princípio, o aprendizado fluiu naturalmente.

Foi uma experiência enriquecedora de aprendizado. As expectativas iniciais como docentes foram atingidas e cada um se viu em um momento único de compartilhamento coletivo.

\section{Referências}

BASTOS, C. C. Metodologias ativas. [S.I.]: Educação \& Medicina, 2006.

BRASIL. Constituição (1967). Constituição Federal da República Federativa do

Brasil. Brasília, DF: Senado Federal, 1980.

BRASIL. Constituição (1988). Constituição Federal da República Federativa do Brasil. Brasília, DF: Senado Federal, 1998.

BRASIL. Lei n. 8.069, de 13 de julho de 1990. Estatuto da Criança e do Adolescente ECA. Diário Oficial da União, Brasília, DF, 16 jul. 1990.

BRASIL. Lei n. 10.097, de 19 de dezembro de 2000. Altera dispositivos da Consolidação das Leis do Trabalho - CLT, aprovada pelo Decreto-Lei $n^{\circ} 5.452$, de $1^{\circ}$ de maio de 1943. Diário Oficial da União, Brasília, DF, 20 dez. 2000. Seção 1, p. 1-2.

BRASIL. Ministério do Trabalho e Emprego. Manual da aprendizagem. Brasília, DF, 2006.

CLAPAREDE, E. Psychologie de l'enfant et pédagogie expérimentale. Géneve: Librairie Kundig, 1909.

CONSELHO ESTADUAL DE EDUCAÇÃO (Alagoas). História da Lei do Menor

Aprendiz. Alagoas, [2009?]. Disponível em: <http://www.cee.al.al.gov.br/ educaçãoprof.html>. Acesso em: 22 ago. 2015.

DELORES, J. Educação: um tesouro a descobrir. São Paulo: Cortez, 2000.

DEWEY, J. Como pensamos. Barcelona: Paidós, 1897.

B. Téc. Senac, Rio de Janeiro, v. 43, n. 3, p. 202-219, set./dez. 2017. 
DECROLY, O. La funció de la globalització i altres escrits. Barcelona: Eumo, 1987.

FAZENDA, Ivani C. A. A interdisciplinaridade: um projeto em parceria. 3. ed. São Paulo: Loyola, 1995.

FREIRE, Paulo. Educação como prática da liberdade. Rio de Janeiro: Paz e Terra, 1986.

FREIRE, Paulo. A importância do ato de ler. São Paulo: Cortez, 1991.

FREIRE, Paulo. Pedagogia da autonomia: saberes necessários à prática educativa. São Paulo: Paz e Terra, 1996.

FREITAS, Katia Siqueira de (Coord.). Pedagogia de projetos. Gerir, Salvador, v. 9 , n. 29, p. 17-37, jan./fev. 2003. Disponível em: <http://www.liderisp.ufba.br/modulos/ pedagproj.pdf $>$. Acesso em: 20 ago. 2015.

HERNÁNDEZ, Fernando. Cultura visual, mudança educativa e projeto de trabalho. Porto Alegre: Artmed, 2000.

HERNÁNDEZ, Fernando. Repensar a função da escola a partir dos projetos de trabalho. Revista Pátio, ano 2, n. 6, p. 27-31, ago./out. 1998.

HERNÁNDEZ, Fernando. Transgressão e mudança na educação: os projetos de trabalho. Porto Alegre: Artes Médicas, 1998.

HERNÁNDEZ, Fernando; VENTURA, M. A organização do currículo por projetos de trabalho: o conhecimento é um caleidoscópio. Porto Alegre: Artes Médicas, 1998.

JOLIBERT, J. Formando crianças leitoras. Porto Alegre: Artes Médicas, 1984.

KILPATRICK, W. H. The project method: teacher's college record. [S.I.: s.n.], 1918. p. 319-335.

LEITE, Lúcia Helena Álvares. A pedagogia de projeto em questão. 1994. Texto produzido a partir da palestra no Curso de Diretores da Rede Municipal de Belo Horizonte, promovido pelo CAPE/SMED em dezembro de 1994.

LEITE, Lúcia Helena Álvares; OLIVEIRA, M. E. P.; MALDONADO, M. D. Projetos de trabalho. In: BRASIL. Ministério da Educação e do Desporto. Secretaria de Educação à Distância. Diários: projetos de trabalho. Brasília, DF, 1998. p. 57-98. Disponível em: <http://www.mec.gov.br/seed/tvescola/pdf/diarios.pdf>. Acesso em: 21 ago. 2015.

LOURENÇO FILHO, Manuel Bergstrom. Introdução ao estudo da escola nova: bases, sistemas e diretrizes da pedagogia contemporânea. 12. ed. São Paulo: Melhoramentos, 1978.

LÜDKE, Menga. 0 trabalho com projetos e a avaliação na educação básica. In: HOFFMANN, J.; SILVA, J. F.; ESTEBAN, M. T. Práticas avaliativas e aprendizagens significativas: em diferentes áreas do currículo. Porto Alegre: Mediação, 2003.

MONTESSORI, Maria. The Montessori method. New York: Frederick A. Stokes, 1912. 
MONTESSORI, Maria. The secret of childhood. New York: Longmans, Green, 1936.

MORIN, Edgar. El método: la naturaleza de la naturaleza. Madrid: Critica, 1977.

MORIN, Edgar. Os sete saberes necessários à educação do futuro. 4. ed. São

Paulo: Cortez, 2001.

NORI, Maria Teresa M. Planejando para desenvolver competências. São Paulo: SENAC/DR/SP, 2000. Texto elaborado para uso no Programa de Desenvolvimento Educacional - PDE.

NOGUEIRA, Nilbo Ribeiro. Pedagogia dos projetos: uma jornada interdisciplinar rumo ao desenvolvimento das múltiplas inteligências. São Paulo: Érica, 2001.

PACHECO, José. Pequeno dicionário de absurdos em educação. Porto Alegre: Artmed, 2006.

PACHECO, José; PACHECO, Maria de Fátima. Escola da ponte. Petrópolis: Vozes, 2008.

SAINZ, F. El método de proyectos. Madrid: Revista de Pedagogia, 1931.

SENAC. DR. SP. Plano de Curso do Programa Aprendizagem em Serviços

Administrativos. São Paulo, 2016. Disponível em: <http://www.intranet.sp.senac.br/ intranet-frontend/portfolio >. Acesso em: 10 out. 2016.

TEIXEIRA, A. Educação não é privilégio. 5. ed. Rio de Janeiro: Ed. UFRJ, 1994.

TEIXEIRA, A. Educação no Brasil. São Paulo: Cia. Editora Nacional, 1969.

TORRES SANTOMÉ, Jurjo. Globalización e interdisciplinariedad: el curriculum integrado. Madrid: Morata, 1994.

TORRES SANTOMÉ, Jurjo. Globalización e interdisciplinaridad: el curriculum integrado. 2. ed. Madrid: Morata, 1998.

VYGOTSKY, L. S. A formação social da mente: o desenvolvimento dos processos psicológicos superiores. 5. ed. São Paulo: M. Fontes, 1996. 